\section{Bir Kitle “ihya” Aracı Olarak Okul}

\section{Salih UÇAK ${ }^{1}$ Zübeyir Gökhan DOĞAN²}

Özet

Okul, yapısı itibariyle işlev ve pratiklere indirgenemeyecek kadar karmaşık bir sistemi tanımlar. İnsanlık, kendi gelişim macerası içinde okulu "çok boyutlu bir yapı" olarak görmüş; gerekliliğini genellikle "hayati” olarak değerlendirmiştir. Son yüzyıla kadar okulun gereksizliğiyle ilgili neredeyse hiçbir ciddi eleştiriye rastlanmaz. Özellikle yeni asrın getirdiği yenilikler, tekçi perspektif, dijital dünya olanakları gibi farklılıklar okulun rolü üzerinde tartışmaların yapılmasına firsat vermiş ve mevcut rolü sıkça gündem olmuştur. Gatto ve İllich gibi düşünürlerin çalışmalarıyla okul üzerinden yapılan değerlendirmelerin haklılık payı söz konusu olsa da dikkatle bakıldığında bunların "olumsuz örnekler" üzerinden geliştirilen eleştiriler olduğu görülecektir. Aracın zengin, amacın fakirleştiği dijital çağda okulun meydan okuyucu bir metafor olarak yeniden kurgulanması gerekir. Makinayı kutsamadan insani olanı hikmetle önceleyen bir okul tasavvuruna ihtiyaç vardır. Bu bağlamda çalışmamız, geleceğin okulunu "her şeye rağmen" insanın yeniden ihyası için en kritik kurumsal olgu olarak kabul etmektedir. Doğal bir sistem olarak okul, aktüel ve popüler "olumsuzlamalara" karşı, geleceği yeniden inşa edecek en güçlü yapı olarak değerlendirilmektedir.

Anahtar kelimeler: Gatto, eğitim, okul, ihya, biçim (tasarım), biçem (estetik).

\section{School as a Mass Revival Tool}

Abstract

The school defines a system that is too complex to be reduced to functions and practices. Humanity saw the school as a "multi-dimensional structure" in its development adventure; its necessity was generally considered to be "vital". Until the last century, there was hardly any serious criticism that the school was unnecessary. Especially the differences such as the innovations of the new century, the monist perspective, the possibilities of the digital world gave the opportunity to discuss the role of the school and its current role was frequently brought up. Even though the evaluations made over the school with the works of thinkers such as Gatto and Illich have a fair share, it will be seen that these are criticisms developed on the basis of "negative examples". In the digital age where the vehicle is rich and purpose is impoverished, the school must be reconstructed as a challenging metaphor. There is a need for a vision of a school that prioritizes the human with wisdom without blessing the machine. In this context, our study regards the school of the future as the most critical institutional phenomenon for human rejuvenation "despite all". School as a natural system is considered to be the strongest structure to rebuild the future against actual and popular "negativities".

Keywords: Gatto, education, school, revival, form (design), style (aesthetics).

1 Dr. Ögretim Üyesi, The University of Georgia / School of Art and Humanities / Department of Oriental Studies / Turcologia Tbilisi/ Georgia, salihucak21@hotmail.com, ORCID: 0000-0001-6650-199X

Lisans eğitimini Malatya İnönü Üniversitesỉnde, yüksek lisans eğitimi Dumlupınar Üniversitesinde, doktora eğitimi Fırat Üniversitesínde Türk Dili ve Edebiyatı alanında tamamladı. MEB'de öğretmen olarak görev yapan Uçak, 2011-2016 yılları arasında Bakanlıklararası Ortak Kültür Komisyonu kararıyla Irak-Erbil Başkonsolosluğu nezdinde Selahaddin Üniversitesi Diller Fakültesi Türk Dili Bölümüne Ögrretim Üyesi olarak görevlendirildi. Belçika, İtalya, Bosna-Hersek, Makedonya, İspanya ve Irak gibi ülkelerde akademik faaliyetlerde bulundu. "Hüsn-i Yusuf” adıyla yayımlanmış bir şiir kitabı, "Birkaç Güzel Adam” ismiyle yayımlanmış bir inceleme kitabı ile bildiri kitaplarında bölüm olarak yayımlanmış eserleri vardır. Halen MEB görevlendirmesiyle Tiflis’te Türkçe okutmanı olarak görev yapmakta ve Ay Vakti dergisinin editörlügünü yürütmektedir

2 Eğitim yöneticisi, MEB Öğretmen Yetiştirme Genel Müd. / Ankara, zubeyirgokhandogan@gmail.com, ORCID: 0000-0002-5193-9910

Lisans eğitimini Atatürk Üniversitesi Eğitim Fakültesỉnde tamamladı. Daha sonra ögretmenliğe başlayan DOĞAN, Uşak Üniversitesỉnde Sınıf Eğitimi alanında master yaptı. 2006-2013 yılları arasında MEB’e bağlı okullarda ögretmen ve yönetici olarak çalıştı. Ulusal ve uluslararası dergide makaleleri yayımlandı. Birçok sempozyum, kongre ve çalıştaylarda bildiri sundu. 2018 yllından bu yana İstanbul il milli eğitim müdür yardımcısı olarak çalışsmaktadır.

\section{Eleştirel Inceleme}

\section{Critical \\ Review}

\section{Künye:}

Kitabın Adı

Eğitim Bir Kitle İmha Silahı

Yazar(lar)

John Taylor Gatto

Çevirmen

Mehmet Ali Özkan

ISBN

978-605-169-173-2

Sayfa Ebatı, Sayıs

$16 \times 23,276$ sf.

Kapak/Kağıt/Renk

Karton Kapak, Kitap Kağıdı,

Tek Renk

Baskı Sayısı ve Yılı

1. Baskı, 2016

Dil

Türkçe

Yayınevi

EDAM

Başvuru/Submitted

3 Eki/Oct 2020

Kabul/Accepted

21 Eki/Oct 2020

Yayın/Published

26 Eki/Oct 2020

ISSN

\section{8-0808}

Atıf/Cite: Uçak, S. ve Doğan, Z. G. (2020). Bir kitle "ihya” aracı olarak okul. Alanyazın, 1(1), 39-46. doi:http:// dx.doi.org/10.22596/ cresjournal.0101.39.46 


\section{Giriş}

Eğitim-öğretim ortamı bağlamında okul, çok sıkça tartışmalara konu olmuş bir olgudur. Eğitimtasarımı dikkate alındığında kendisiyle barışık olan bireylerin oluşturduğu bir okul için diğer bütün işlevler gibi fiziki alanın etkin bir biçimde kurgulanması elzemdir. Okul tasarımı ve estetiği konusunda mekânın sosyokültürel kimliği ile eğitime yansıyan "saydamlık" ilkesi, son zamanlarda ciddi bir biçimde gündem olmaktadır.

$\mathrm{Bu}$ çalışma, başlı̆̆ından da anlaşılacağı üzere Gatto’nun bütün dünyada olduğu gibi ülkemizde de eğitim çevrelerinde ilgiyle karşılanan ünlü eseri Eğitim Bir Kitle İmha Silahı adlı

Zorunlu Eğitimin Karanlık Dünyasında Bir Yolculuk
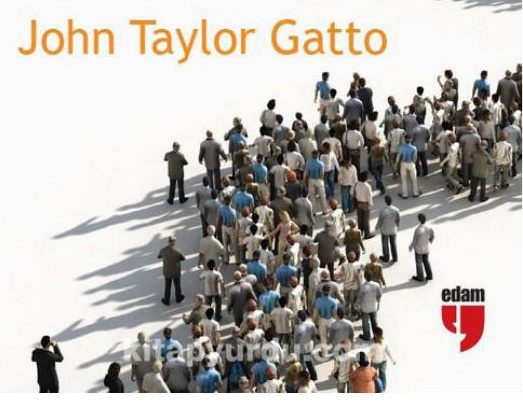
çalışmasından mülhemdir. Bu eser ne bir reddiye, ne de tanıtımdır. Daha çok referans noktası olarak Gatto'yu merkeze alan genel bir değerlendirmedir.

Gatto, zorunlu eğitim üzerinden okulun 'hizaya sokma' işlevini şiddetle eleştirir. Okula gerçekten ihtiyacımız var mı bizim? derken, hem öğrenciler hem de öğretmenler için hücre hapsinden başka bir şey olmayan okulun yeniden düşünülmesi gerektiğini hatırlatır (Gatto, 2019, s. 19-20). Ev okulu ve açık kaynak önerilerini göstererek temelde insanı otomatlaştıran zorunlu eğitime muhalif bir dil geliştirir. Onun yaptığı şey aslında bir sistem eleştirisidir. Bir dönem eğitimin tanımında da yer alan 'istendik yönde davranış değişikliği’ni, öğrencinin bütün özgünlüğünü ve yaratıcılığını yok eden bir silah olarak yorumlar. Eğitim, öğrenciyi törpüleyen bir olgu olmak yerine, ona ufuk kazandıran bir süreci ifade etmelidir.

Okul, yapısı itibariyle

işlev ve pratiklere

indirgenemeyecek kadar

karmaşık bir sistemi

tanımlar.

Kamusal eğitim misyonunu yerine getirmek üzere kurulan 'formal okul'un bireyi tehdit oluşturmayacak bir düzeyde tutmak, standartlaşmış bir vatandaş öğretisi yaymak, başkaldırı ve özerkliği öldürmek gibi görevleri vardır (Gatto, 2019, s. 25). Bu sert eleştirilerin yadsınamaz tarafları olsa da okul, bütün dönemlerin en vazgeçilmez kurumlarından biri olduğu muhakkaktır.

Ancak okulun işlevleri konusunda yapılan tartışmaların haklılık payının okulun 'çıktısının insan' oluşundan kaynaklandığını da söylemek durumundayız. İnsani macerada karşımıza çıkan her 'olumsuzluğun' tartışmasız müsebbibi eğitim olunca bu tartışmalar da kaçınılmaz olmaktadır. Zira eğitim sistemleri, müfredatlar, gelecek nesil projeksiyonları ve süreçler bu alanın daima 'aktüel bir mesele' olarak kalmasını sağlamıştır.

Gatto, 'mış gibi yapılan eğitimle' zihinlerin iğdiş edilerek tüketimin emrine verildiğine dair tespitlerde bulunur. Tüketim kültürüne yenilen nesiller, kendilerini gerçekleştirmekten 
uzaklaşmakta, tüketim çılgınlığının pençesine düşen kurbanlara dönüşmektedirler. Zorunlu eğitimle çocukların kan bağıyla bağlı oldukları ailelerinden alınarak toplum uzmanlarının himaye ve gözetimine verildiğine dikkat çeken Gatto, okulu bilgiyi karneyle dağıtan kurum olarak tanımlamaktadır. Bu bakımdan okul, tüketimi kolaylaştıran alışkanlıklar kazandırmakta, zil ve komutlarla öğrenciyi

Aracın zengin, amacın fakirleştiği dijital çağda okulun meydan okuyucu bir metafor olarak yeniden kurgulanması gerekir. harekete geçirmektedir. $\mathrm{Bu}$ şartlanmışlıkla üretimin nihai hedefi olan 'kendini üretmek' becerisinin asla mümkün olmayacağını hatırlatır (Gatto, 2019, s. 91). Eleyen ve yaftalayan eğitim sistemleri ile okulun misyonu bağlaminda kitlesel eğitim argümanlarını yeniden düşünmek zorundayız. Maarif davasına mesai harcayan Nurettin Topçu, okul ve ögrrenci bağlamında Gatto'ya yaklaşan bir tespitte bulunur. Ona göre öğrenci, hakikat peşinde koşmayı meslek edinen insandır, gayesi manevi olgunlaşma olan bir mesleğin insanıdır, mekteplerin diploma müşterisi ve istikbalin mevki dilencisi değildir (Topçu, 2016, s. 114). Bu gözle değerlendirildiğinde 'yanlışın' genel bir doğru haline geldiğini itiraf etmek zorunda kalırız. Özeleştiri yapmak ve okulu gerçek misyonuyla yeniden düşünmek aslî ve asrî görevimizdir. Okulun himayesine verilen her öğrencinin kendini üretebilecek bir ufka sahip olması için kartların yeniden karılmasına ihtiyaç vardır.

İllich, hâlihazırda var olan okulu eleştirirken özellikle pratik değerlere ait bir kazanım sağlamadığı için sisteme ve okul programlarına dikkat çeker. Tıpkı Gatto gibi İllich de okulun bireyi özgürleştirmediğini, sistemin ve toplumun onayladığı bir birey haline dönüştürdügünü söyler (İllich, 2013). Okulların öğrenciye 'değer' kazandırmak yerine 'hizmet' sektörünün gerektirdiği özellikleri kazandıran bir nitelik taşıdığını ve bu yönüyle de eğitim verdiğini ancak öğretim yapma imkânının olmadığını hatırlatan İllich, zengin-fakir, getto-banliyö bağlamında adaletsiz bir sistemin var olduğunu dile getirir. Ona göre 'zorunlu eşit okullaşma ekonomik olarak uygulanamaz' bir gerçektir. İllich'in getirdiği bir diğer eleştiri, okul sisteminin insanlara eşit şanslar vermek yerine, imkânların dağılımında tekelleşmeye yol açmasıdır (İllich, 2013). Okulu, sonsuz tüketim mitinin başlangıcı kabul eden İllich, edinim ve öğrenme kavramlarından yola çıkarak yeni bir eleştiri getirir. Ona göre asıl olan

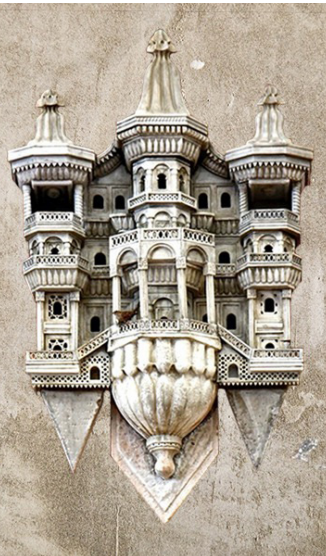
edinimdir. Çünkü edim bireyin kendi çabasına bağlıdır ve kendiliğinden oluşur. Öğrenme ise dışardan bir etkiyle meydana getirilmeye çalışılan ve kalıcılığı olmayan yetidir. Bu sebeple okul edinim yeri değil, öğrenme odaklı bir yapıyı temsil etmektedir. İllich, 
okulun 'değer' olarak aşıladığı her şeyin sayısal bir karşılığının olduğunu; hâlbuki bireysel gelişimin herhangi bir meta ile ölçülemeceğini söyler (İllich, 2013, s. 62-64).

Çağdaş toplumların sosyo-politik tasarımlarının çoğunlukla bilinçli bir mühendislik ürünü olduğu gerçeğinden hareket edilirse 'birey' bağlamında Gatto ve İllich’in okul olgusuna getirdiği eleştiriler yabana atılacak tezler değildir. Lakin toplumların içinde bulunduğu şartlar, gelişmişlik düzeyi, sosyo-ekonomik göstergeler bize okulun hâlâ vazgeçilemez bir gereklilik olduğunu hatırlatmaktadır. Kurumsal bir yapı olarak okulun yeniden ele alınması, bütüncül bir iyileştirmeye tabi tutularak 'ideal' bir okul için yapılması gerekenler aktüel olarak elbette tartışmaya açık bir konudur.

\section{Biçim mi, Biçem mi?}

İdeal okul tasarımı var mıdır, varsa nasıldır? Kim için okul? Kimin okulu? Bunun gibi sorular, biçim ve biçem bağlamında okulun bir bütün olarak yeniden ele alınmasına işaret eder. Okulun bütünselliği, öğrencinin fiziksel, ruhsal, bilişsel ve sosyal bütünlüğüyle doğrudan bağlantılıdır. Okul tasavvurları bakımından ortaya atılan kapsayıcı okul kavramı, öğrencinin evden çok okulda geçirdiği topyekûn zaman dikkate alındığında daha doğru anlaşılacaktır. Okul, metaforik mekan kimliğiyle irdelendiğinde keşfe ve yeni öğrenmelere açık bir yapıyı akla getirmelidir. Sınırlara ve standartlara bağlı bir okul algısı, z ve alfa nesli için büyük bir ihtimalle çekilmez bir yer düşüncesine evrilecektir.

Gatto; eğitim, duvarlarla çevrili yerleşkelerle alakalı bir şey değildir (Gatto, 2019, s. 9) derken biraz da okulun bu boyutlarına dikkat çekmektedir. Eğitim, herkesten ve her şeyden öğrenmeyi mümkün kılan açık ögrenme sistemidir. O halde okulun 'kutu mimarisi' üzerinden geliştirilecek 'yükseklik-alçaklık, eniboyu' argümanları kadar; "ideal okul” düşüncesi üzerinden yapilacak plan ve programlara ihtiyaç vardır.

Toplumun kendi okulunu tasarlaması için bütün bileşenlerinin bir araya gelmesi şarttır. Mimarın pedagogu, öğretmenin öğrenciyi, velinin öğretmeni, sistemin bütün paydaşları dikkate aldığı bir okul vizyonu,

\section{Toplumun kendi okulunu} tasarlaması için bütün bileşenlerinin bir araya gelmesi şarttır. Mimarın pedagogu, öğretmenin öğrenciyi, velinin öğretmeni, sistemin bütün paydaşları dikkate aldığı bir okul vizyonu, eğitimin geleceğini/geleceğin eğitimini müjdeleyebilir. Bütün bileşenlerin birbirini ötekileştirmeden, olduğu gibi kabul ettiği 'huzurlu okul' tasarımının konuşulması bu sayede mümkün olabilir. 
eğitimin geleceğini/geleceğin eğitimini müjdeleyebilir. Bütün bileşenlerin birbirini ötekileştirmeden, olduğu gibi kabul ettiği 'huzurlu okul' tasarımının konuşulması bu sayede mümkün olabilir.

Öğrencinin bilişsel, fiziksel ve psiko-sosyal gelişimini etkileyen okul tasarımında söz

Makinayı kutsamadan insanî olanı hikmetle önceleyen bir okul tasavvuruna ihtiyaç vardır. mimariye düşecekse bütün duyulara hitap eden

bir disiplin olarak mekânı keşfe kapı aralayan bir yapı olarak görmek durumundayız. Yapıdaki milli ve evrensel ilkelere ait dokunuşlar, öğrencinin etik ve estetik gelişimini önceleyen özgünlükte olması kapsayıcı okul bağlamında önemlidir. Ancak okulu düşünürken hangi şartlara, hangi imkânlara bağlı düşünmemiz gerektiğini göz önünde tutmak zorundayız. Gelişmiş ülkelerdeki okulu baz aldığımızda akustik, havalandırma, ısı-sıcaklık dengesi, hijyen ve ergonomi pekala konuşulabilir. Lakin imkân ve şartlar itibariyle az gelişmiş bir ülke temel alındığında bütün bu kavramların hiçbir değer ifade etmediğini itiraf etmek gerekir. Ülkemiz ve gelişmiş ülkeler ışığında yaptığımız değerlendirmelerde biçim ile biçemin iç içe geçen iki vazgeçilmez unsur olduğu görülebilmektedir. Eğitimdeki ihtiyaç hiyerarşisi, biçim ile biçemin önceliklerini değiştirebilir.

\section{İmha mı, İhya mı?}

Eğitim, günümüzde çok boyutlu bir evreni ifade etmektedir. Tek yönlü, tikel bir organizasyon değil, çoğulcu ve tümel bir olgu olarak yeniden tanımlamayı ve yeni paradigmalarla üzerinde düşünmeyi zorunlu kılmaktadır. Bu bağlamda öğrenme ve araştırma faaliyetleri okulu, öğretmen ve öğrencileri yeni rollere yönlendirmektedir. Değişen, dönüşen ve teknolojide her gün yeni bir oluşuma evrilen dünyada; yeni bakış açılarına, yüzyılın gerektirdiği donanıma ihtiyaç vardır. Uzun bir süreç olarak kabul edilen eğitimin süreklilik arz etmesi, uzun vadeli eğitim politikalarından günlük kazanımlara varıncaya kadar eğitimi yeniden düşünmenin bir gereklilik olduğu anlaşılmaktadır.

Çok boyutlu bir evren olarak tanımlanan okulun öznesi 'insan/öğrenci'dir. Okulun gizliaçık bütün amaçlarını gerçekleştirecek ana unsur ise öğretmendir. Bir 'model' oluşturma

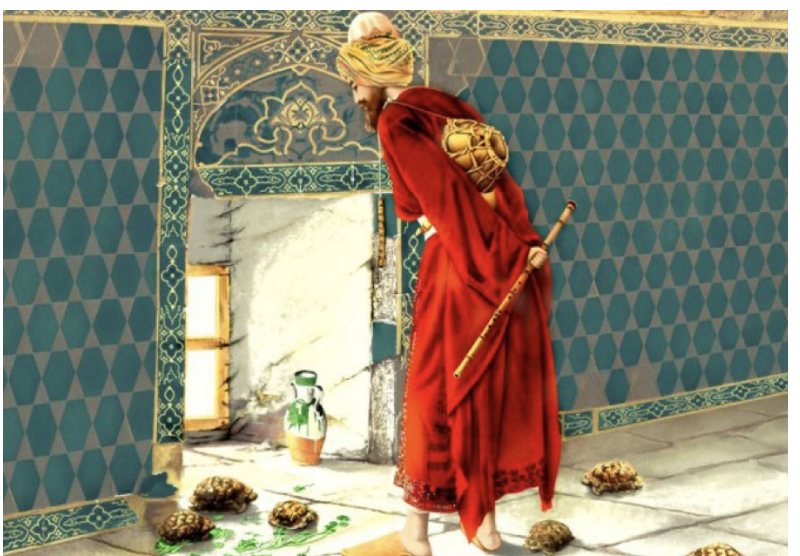
gayesiyle yapilacak her plan ve programda özne ile model arasındaki bağın gücü bütün bileşenlerden çok daha etkili ve önemlidir. Ancak, öğretmen yetiştirme politikaları başta olmak üzere girdi-çıktılarına varıncaya kadar eğitimle ilgili her bileşen onu doğrudan etkilemektedir. $\mathrm{Bu}$ noktada Gatto, formal okulun ögrrenci üzerindeki olumsuz tesirlerini 
öne çıkararak burada verilen eğitimin çocuklara işçi ve tüketici olmayı öğrettiğini, onların lider ve maceracı olmalarına engel olduğunu söyler (Gatto, 2019, s. 29). Bu yönüyle okul, itaat etmeyi ögrreten, eleştirel ve bağımsız düşünmeyi yadsıyan bir kurum olarak kabul edilir. Hâlbuki öğrenci ve öğretmenlerin ' 21 . yüzyıl becerileri' olarak tanımlanan problem çözme, eleştirel düşünme, iletişim becerisi, işbirliği ve özyönetim gibi becerileri kazanabilmeleri için okul, tartışmasız en ergonomik kurumdur. Bu durumda hangi okul? sorusuna verilecek kapsayıcı cevap, sorunun çözümü bağlamında ipuçlarını da taşıyacaktır. Ancak en kestirme cevabın 'imha eden değil, ihya eden okul' olduğunu söylemek gerekir.

Gelecek projeksiyonlar ışığında 2023 Eğitim Vizyonu Belgesindeki temel amaca bakıldığında; çağın ve geleceğin becerileriyle donanmış ve bu donanımı insanlık hayrına sarf edebilen, bilime sevdal, kültüre meraklı ve duyarl, nitelikli ve ahlaklı bireyler yetiştirme gayesinin vurgulandığ görülecektir. Gatto'nun özellikle ABD'deki okullar özelinde zorunlu eğitimin öğretimi bir silah olarak kullandığını söylemesi insan ve makina, insan ve tüketim arasındaki ilişkiye yeniden bakmayı gerektirmektedir. Ona göre okul, okuma yazma, aritmetik ve terbiye yeri olmaktan çıkıp endüstriyel tüketimin çarklarına teslim olunan bir yere dönüşmüştür(Gatto, 2019, s. 51).

Öznenin içinde yaşadığı çevre/mekân onun kişilik oluşumunu ve davranışlarını şekillendirir. Topçu, Gatto'nun bahsettiği tehlikeyi millilik ruhuyla bertaraf etmeyi düşünür. Ona göre Avrupalı gibi makine aşı̆̆ı değil, ruh ve vicdan aşığı yetiştirmenin yolu, oradan alınan metotların değişiminden geçer (Topçu, 2016: 117). Maarifte işlenen ilmi suikastların bitmesi ve istenilen neslin yetişmesi için özgün bir maarif sistemini kurmaya mecburuz. 'Aşk ile inanışın terbiyesini almamış nesiller, bedbaht nesillerdir;' ihya eden bir eğitim sistemi, yarınımızdır.

Maarif davasına katkı sunan mütefekkir Necip Fazıl tıpkı Topçu gibi; yenilgi, yılgınlık duygusu ve aşağılık kompleksi içindeki gençlikten “inşası yolunda kan terlediği” yeni bir gençlik yaratmak idealini savunmuştur: "Yeterince Türk, yeterince Müslüman, yeterince kişilikli, güvenli ve aksiyoner bir gençlik (Erkilet, 2005, s. 66) bütün bir hayatın ihyası anlamında önemsediği bir düşüncedir. Çağın olumsuzluklarına karşı koymak, şuurlu gençlikle mümkündür.

Okul ikliminde 'her öğrenci özel ve biriciktir' ifadesi ezberlenen bir mottoya dönüşse de uygulamada eksikliklerin yaşandığı bilinen bir gerçektir. Nesil kaybına tahammülün olmaması gereken en önemli yer hiç şüphesiz ki okuldur. İletişim sorununu çözmüş bireylerin oluşturduğu okul iklimi, geleceği muştulayan bir umudu diri tutabilir.

Bugün okullarda eğitimden çok öğretimin var olması, sistem ve gelecek bağlamında en ciddi handikapları oluşturmaktadır.

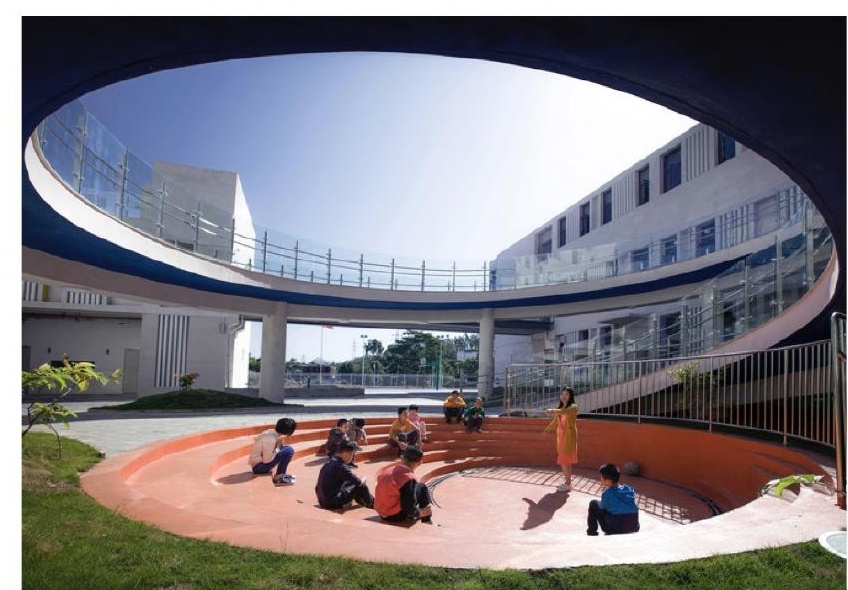


Öğretimin karneye ve sınava dönüşen zorunlu eleyici ve yaftalayıcı boyutu, ideal olanı riske atmaktadır. 'Asım'ın Nesli' gibi bir gençlik tasavvuruna sahip olan Akif' in en büyük isyanı, gençliği gelecek korkusuyla yıldırmak, onu ümitsizlik yoluna sevk etmektir:

Eğitim öğretim ortamı bağlamında okul, çok sıkça tartışmalara konu olmuş bir olgudur.

Daha mektebe çocuktuk, bizi yıldırdı hayat;

Oysa hiç korku nedir bilmeyecektik, heyhat!

Neslim ürkekmiş, evet, yoktu ki ürkütmeyeni;

"Yürü oğlum!" diye teşcî' edecek yerde beni,

Diktiler karşıma bir kapkara müstakbel ki,

Öyle korkunç olamaz hortlasa devler belki! (Ersoy, 2007, s. 788.)

Asım, ilim irfan sahibi, karakterli, ahlaklı ve zorluklara göğüs geren bir gençtir. Onun için’ gelecek korkusu' yoktur. Mülkün gerçek sahibinin kim olduğunun farkındadır. Bu yüzden aslî gaye için fani olanı tercih etmez. İyi bir doktor, iyi bir mühendis değil 'iyi ve ahlaklı bir insan modeli' yetiştirme politikası bizi gerçeğe daha çok yaklaştıracaktır. Sezai Karakoç'un ihya edici manifestosu Diriliş'te herkesi 'bir neslin amentüsüne' davet eder: 'Bu amentü, sürekli bir otokritiktir. Kendi benliğini ve varlığını erdem ve takva açısından tartışmadır. En duyarl terazilerde kendini tartma demektir. Bu amentü, hakikatin sırrına ermek için sürekli bir özeleştiridir.' Bu amentüyle yola koyulan her diriliş eri, hidayet ve nasibince diriliş piri oluncaya kadar azmeder durur (Karakoç, 1995, s. 8-10). Ön yargılardan uzak çok renkli çok kültürlü hayata donanmış bir ruhla katılmak, güçlü yarınlar oluşturmak demektir. İhya edici okul sisteminde öğrenciler aktif öncüler olarak kurallar ve standartlarla sinırlandırılmadan 'kendileri olabilme' imkânına sahip olurlar. Karakoç'un dikkat çektiği 'diriliş yolu, uğurlu, iyilikçi bir topluluğu gerçekleştirme yoludur.' Diriliş eri 'erdem sitesinin' yılmaz neferi, diriliş yolunun yorulmaz işçisidir (Karakoç, 1995, s. 7).

Gatto, öğrenciye zarar vermek kastıyla kurulup işlerlik kazanmış “silah” metaforuyla okulu (Gatto, 2019, s. 165) tanımlarken aslında onun ne kadar stratejik bir kurum olduğuna da işaret etmektedir. Bu bakımdan okulu yeniden düşündüğümüzde onu imha eden değil, her yönüyle özneyi ihya eden bir kuruma dönüştürme görevi, başta kurumsal yapı olmak üzere bütün eğitim bileşenlerine düşmektedir.

\section{Sonuç}

Eğitim odaklı dijital çağın karmaşık gereksinimleri ihya edici bir vizyon ve misyon ile giderilebilir. Nesiller için ideal olanı bulma gayreti, başta muallimler olmak üzere herkesin ödevidir. Hayatın bütünselliği içinde meseleyi doğru okumak gibi bir zorunluluğumuz vardır. Karar alma süreçleri, karar alıcılar tarafından çok büyük bir titizlikle ele alınmalıdır. 
Mesele nesil olduğunda hiçbir tesadüfe yer bırakmayacak şekilde doğru ve net kararlar alınmalıdır.

Genç dimağlara özgün düşünebilme eğitimi verilmeli ve taklitten kaçınmanın gerekliliği teferruatıyla anlatılmalıdır. Eğitimin bu konudaki rolü ile paydaşların sorumluluğu göz önüne alınmalıdır. Anlamsızlık, bugünün gençliğini en çok meşgul eden meselelerden biridir. Kendilik şuurunu yakalayamamış pek çok genç insan, bu anlamsızlık duygusunu yaşar. Şayet bu duygu zamanında ve doğru bir şekilde 'anlamlı olana' devşirilemezse ülküsüz bir gençlikle karşı karşıya kalmak zorunda kalacağız. Bu nedenle bir kitle ihya aracı olarak okulu bütün boyutlarıyla yeniden ele almak durumdayı.

Gatto ve İllich'in ileri sürdügü fikirlerin 'olumsuz örneklerden genellemelere' gittiğini tespit etmek zor değildir. Bu bakımdan bütüncül bir bakış açısıyla okulun ve dolayısıyla eğitimin yeniden tasarlanması mutlak bir gerekliliktir. Misyon bağlamında çağı yakalayan, vizyon bakımından geleceğin gerçekliğini öngören bir okul, nesil davası güden her toplum için hayati bir konudur.

Eğitim, bir öncelik meselesidir. Nitelikli bir eğitimin evrensel gerçekliği kadar milli olma dengesi gözetilmelidir. Eğitim için sistem ve politika üretmek, okulun girdi-çıktılarını sürekli bir biçimde değerlendirmek bir mecburiyettir. En iyi olana ulaşma gayesiyle ön almak başta politika yapıcılar olmak üzere bütün paydaşların sorumluluğudur. Toplumu ihya edecek okulun insani boyutu, her şeyin üstündedir. Dolayısıyla sürecin, makinanın, teknolojinin veya tüketimin öngördüğü bir okul değil, insanı ontolojik olarak kendi asli çizgisine yaklaştıran bir okul düşüncesinin inşa edilmesi gerekmektedir.

\section{Kaynaklar / References}

Erkilet, A. (2005). Büyük Doğu nereden doğar. Hece (97).

Ersoy, M. A. (2007). Safahat. İstanbul: Beyan.

Gatto, J. T. (2019). Eğitim bir kitle imha silahı. İstanbul: Edam.

İllich, İ. D. (2013). Okulsuz toplum. (M. Özay, Çev.) İstanbul: Şule.

Karakoç, S. (1995). Diriliş neslinin amentüsü. İstanbul: Diriliş.

MEB. (2018). MEB, 2023 Vizyon Belgesi. Ankara: MEB.

Topçu, N. (2016). Türkiyénin maarif davası. İstanbul: Dergah. 